\title{
SPATIOTEMPORAL PATTERNS AND SOCIOECONOMIC DIMENSIONS OF SHARED ACCOMMODATIONS: THE CASE OF AIRBNB IN LOS ANGELES, CALIFORNIA
}

\author{
A. Sarkar ${ }^{\text {a, * }}$, M. Koohikamali a, J.B. Pick ${ }^{\text {a }}$ \\ ${ }^{a}$ University of Redlands, School of Business - (Avijit_Sarkar, Mehrdad_Koohikamali, James_Pick) @redlands.edu
}

KEY WORDS: Sharing Economy, Airbnb, Socioeconomic, Spatiotemporal, Los Angeles, Spatial Autocorrelation, Regression

\begin{abstract}
:
In recent years, disruptive innovation by peer-to-peer platforms in a variety of industries, notably transportation and hospitality have altered the way individuals consume everyday essential services. With growth in sharing economy platforms such as Uber for ridesharing and Airbnb for short-term accommodations, interest in examining spatiotemporal patterns of participation in the sharing economy by suppliers and consumers is increasing. This research is motivated by key questions: who are the sharing economy workers, where are they located, and does their location influence their participation in the sharing economy? This paper is the first systematic effort to analyze spatiotemporal patterns of participation by hosts in the shared accommodation-based economy. Using three different kinds of shared accommodations listed in a 3-year period in the popular short-term accommodation platform, Airbnb, we examine spatiotemporal dimensions of host participation in a major U.S. market, Los Angeles CA. The paper also develops a conceptual model by positing associations of demographic, socioeconomic, occupational, and social capital attributes of hosts, along with their attitudes toward trust and greener consumption with hosts' participation in a shared accommodation market. Results confirm host participation to be influenced by young dependency ratio, the potential of supplemental income, as well as the sustainability potential of collaborative consumption, along with finance, insurance, and real estate occupation, but not so much by trust for our overall study area. These results add new insights to limited prior knowledge about the sharing economy worker and have policy implications.
\end{abstract}

\section{INTRODUCTION}

In recent years, sharing economy platforms have disrupted and revolutionized traditional business models and paradigms in sectors such as transportation, banking and finance, retail, food and hospitality, healthcare to name a few (Sundararajan 2016). Companies that facilitate sharing have grown rapidly in many industries to the point that ridesharing companies such as Uber and Lyft, shared accommodation platforms such as Airbnb and HomeAway, and social eating platforms such as Feastly and EatWith are becoming household names.

Concomitant with the rise in sharing economy platforms and their usage is academic interest in examining many aspects of sharing or collaborative consumption - from social dimensions to economic impact, regulatory needs, consumer protection, to the emergence of a potential new digital divide, and from motivations to participate in sharing to implications of diversification and exploitation of labor. A key question of interest in the context of diversification of labor in the sharing economy is - who participates in the sharing economy? Both supply- as well as demand-side participation are intrinsic to collaborative consumption. For example, in the case of shared accommodations, an Airbnb host is a renter (supplier) who chooses to rent or share his/her entire home, apartment, or room with a guest (consumer who engenders demand) for a limited period of time. What are the demographic and socio-economic attributes of these shared accommodation participants? What are their motivations to participate in the sharing economy? These questions are of interest not only to sharing economy platforms, they are equally important to governments interested in consumer protection and public policy, businesses that are competitive or complementary to sharing economy service providers, and to researchers.

In this paper, we focus on host (i.e., supply-side) participation in shared accommodation-based economy. In examining associations of independent correlates with the dependent indicators of host participation in shared accommodations, it becomes imperative to examine spatiotemporal underpinnings of such participation. Specifically, it is essential to account for bias introduced due to spatial autocorrelation of the dependent indicators of participation, estimated in this study by densities of Airbnb property listings. Without accounting for spatial bias, regression-based associations of demographic, socioeconomic, occupational, social capital, and attitude-related independent variables with shared economy participation may be misleading. Therefore, the research questions of this study are: (1) what are spatial and temporal patterns of host participation in the shared accommodation-based economy in the greater Los Angeles area between 2015 and 2017? (2) Are geographic agglomerations of host participation in shared accommodation based economy present in the greater LA area as estimated by cluster and outlier analysis? (3) What are the associations of demographic, socioeconomic, occupational, social capital variables as well as attitudes towards trust and greener consumption with host participation in shared accommodation-based economy in the greater Los Angeles area and the city of Los Angeles? (4) Can a regression model of such associations account for presence of spatial bias in participation?

\section{LITERATURE REVIEW}

The way consumers access, buy, and use products and services is changing (Matzler et al. 2015). Temporary access to products and assets instead of permanent ownership through buying is sharing economy (Matzler et al. 2015). Information technology (IT) has made the shaping of sharing economy faster because of availability of digital information, IT growth, and higher flexibilities of new forms of IT (Sundararajan 2016, pp.52-53). People are able to trade goods and services on a peer-to-peer online marketplace of modern sharing economy in exchange of certain fees (Sundarajan 2013). Sharing economy's main pillars are based on its simple platform to exchange goods and services, high impact on capitals, decentralized networks of people, and unclear distinction between fully employed and causal labor

\footnotetext{
${ }^{*}$ Corresponding author
} 
(Sundararajan 2016, pp.47). In modern cities, people are willing to participate in sharing as a result of limited resources/assets or less availability of new value creations (Sundararajan 2013, 2016).

Three major motives behind sharing economy participation are based on economic, environmental, and locational factors (Bocker and Meelen 2016). Several studies conducted recently to investigate different aspects of sharing economy including intentions to participate (Kim et al. 2015; Zhang et al. 2016), positive impact of trust on sharing economy participation (Mittendorf 2017), positive sustainability motivation influence on attitude toward sharing economy (Hamari et al. 2016), community belonging relationship with sharing economy selection (Möhlmann 2015), and locational amenities' impact on service providers' actual participation (Koohikamali et al. 2017). Gutierrez et al. (2016) is one of relatively few studies focusing on spatial distribution of Airbnb accommodations. Findings of this study demonstrate different spatial distributions of Airbnb and hotel accommodations in Barcelona, Spain. Accommodation dominance of Airbnb over hotels is apparent in city's main tourist attractions, which is inverse in some peripheral areas of the city (Gutierrez et al. 2016). While sharing economy is more/less developed in different locations of the city, it is not clear why and when people decide to participate in sharing economy.

Three recent reports provided insights on different negative consequences of sharing economy. A Bloomberg brief explores some economic implications of sharing economy in the US (Rossa et al. 2015). This report shows business models in certain industries (e.g. cars and hotels) are disrupted. In addition, economists should consider informal employment made possible on sharing economy platforms when analyzing data (Rossa et al. 2015). The report indicates that benefit of Airbnb is more for travelers than for cities (Rossa et al. 2015). Second, a Federal Trade Commission report discusses issues of sharing economy, as an innovative disruption (Ramirez et al. 2016). This report shows internet and smartphone adoption and usage have reshaped related services to benefit consumers and suppliers, but not the traditional incumbents of those services. Finally, Pew Research Center report on sharing economy provides insights into raising difficult issues around some jobs and emergence of a new digital divide (Smith 2016). The report indicates 73\% of Americans are still unfamiliar with sharing economy. Among users who are familiar with issues on changing nature of some jobs, $42 \%$ do not believe the service should follow the same regulation as existing traditional service providers, while 35\% felt the opposite (Smith 2016).

Overall, other than a few reports, the examination of spatiotemporal patterns of host participation in the sharing economy, specifically shared accommodation-based economy is largely absent from the academic literature. This study is also novel since it is the first systematic effort to develop a model and empirically analyze the influences of demographic, socioeconomic, occupational, social capital variables along with the influence of hosts' attitudes towards trust and green consumption for a large metropolitan area. Next, we present our conceptual model of host participation in shared accommodation-based economy.

\section{CONCEPTUAL MODEL OF HOST PARTICIPATION IN SHARED ACCOMMODATION-BASED ECONOMY}

The conceptual theory for this study is a spatially aware model of participation in the shared accommodation-based economy. The model posits associations of 17 demographic, economic, educational, social capital, and attitude-related influences on sharing economy participation - estimated by 16 dependent variables. The model includes exploratory analysis of spatial as well as temporal patterns of shared accommodations, demonstrating geographic agglomerations or clusters of high ("hotspots") versus low (“coldspots”) densities of Airbnb listed properties. Additionally, there is confirmatory measurement of the effects of the independent factors on each of the participation (measured by density of property listings) dependent variables, and accounting for spatial bias. Spatial bias refers to influences that strengthen or weaken the findings of associations due to similarities or differences of spatial agglomeration of the dependent variables, without controlling in the model for the agglomerations. Usually such bias is positive and the findings are exaggerated, so independent factors appear more important than they really are.

Similar models such as the Spatially Aware Technology Utilization Model (SATUM) have been employed to examine socioeconomic, demographic, innovation, societal openness, and social capital's influences on the adoption, diffusion, and utilization of information and communications technologies, and implications for digital divides (Pick and Sarkar 2015).

The conceptual model of host participation in shared accommodation-based economy (Figure 1) consists of six categories of independent factors, and is comprised of 17 independent variables and 16 property density estimates of host participation in shared accommodations. The model is exploratory since demographic, socio-economic, occupational and other influences on shared economy participation have had little data-driven empirical analysis. The remainder of this section justifies the inclusion of the independent variables in the model. Subsequently, the section introduces the dependent variables of the conceptual model.

\subsection{Independent Variables in Conceptual Model}

Demographic variables: Recent reports of the Pew Research Center (Smith 2016) and Bloomberg (Rossa et al. 2015) have shed light on demographic attributes of sharing economy participants. While the Pew sharing economy report has focused mainly on consumers (Smith 2016), Rossa et al. (2015) found sharing economy workers overall to be younger, ethnically similar, and more male compared to the U.S. workforce. Somewhat in contrast, the same report indicated Uber drivers to be much more similar in terms of age to the general workforce than to traditional taxi drivers and chauffeurs. Therefore, we posit young dependency ratio (Pop. Age 0-19/Pop. Age 20-64) and gender ratio (Male Pop./Female Pop. Age 21+) to be positively associated with sharing economy participation. From a race/ethnicity standpoint, Hispanics, Blacks, and Asians (in that order) were found to lag far behind Whites as sharing economy workers. Additionally, the proportions of White, Hispanic, Black, and Asian sharing economy workers largely corresponded to the proportional representation of the four race/ethnic groups in the U.S. workforce. Coupled with evidence that sharing economy workers are often motivated by supplemental income opportunities, we posit Black and Hispanic to be positively associated with shared accommodation participation (i.e., due to negative correlation between Black and Hispanic with income), and Asian to be negatively associated with shared accommodation participation.

Economic variables: Recent studies reveal that the sharing economy can provide workers with primary incomes, supplement other income, or carry them through periods of unemployment. In 
particular, Airbnb hosts described renting their residences, often staying with their guests, and the importance of the additional income this activity provided. Uber and Lyft drivers worked parttime to augment their income from other work (Ramirez et al. 2016) Since higher income is likely to dissuade the search for supplemental sources of income, we posit median household income to be negatively associated and per capita owner occupied households with a mortgage, an indicator of financial stability and economic well-being, to be negatively associated with shared accommodation participation.

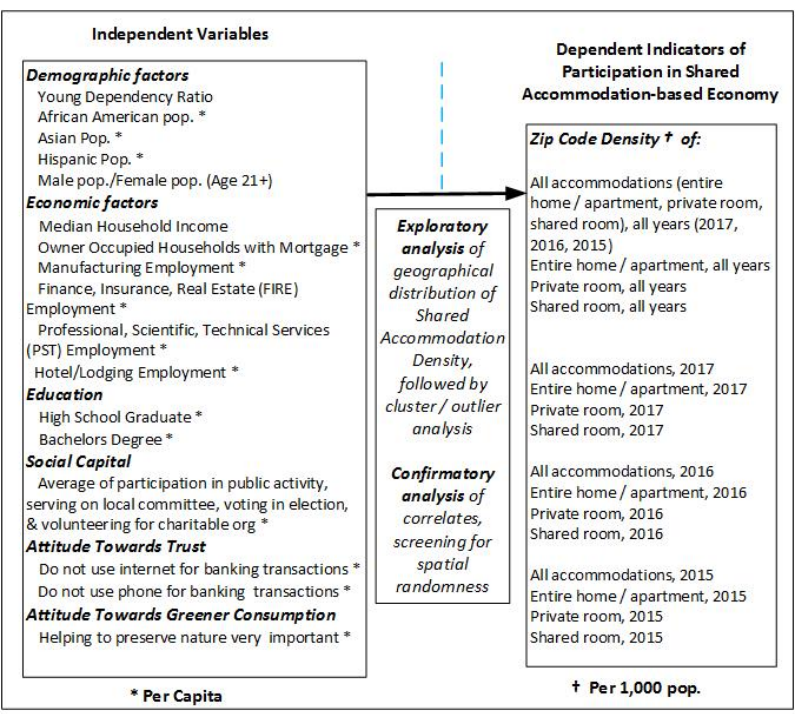

Figure 1. Conceptual model of host participation in shared accommodation-based economy

Recent reports have also indicated that some startups are trying to usher white-collar workers into the on-demand economy as employees, rather than as customers (Benner, 2015). Additionally, with evidence that sharing economy workers are likely to be more educated in comparison to the U.S. population (Rossa et al. 2015), we posit traditionally white collar occupations - finance, insurance, and real estate (FIRE), and professional, scientific, and technical services (PSTS) to be positively associated with shared accommodation participation. We posit hotel/lodging employment to also be positively associated with shared accommodation participation and reason that those experienced in the hospitality industry are more likely to be Airbnb hosts, especially when coupled with the motivation to supplement or augment their primary income.

Education variables: Due to reasons stated before, we posit high school graduates and college education (bachelors) to be positively associated with shared accommodation participation.

Social Capital: Social capital, often an indicator of social connectedness of communities and individuals has been found to positively influence internet use among U.S. individuals (Chen 2013) and U.S. states (Pick et al. 2015). Social capital has been posited to provide material access to the internet as well as access to resources that are skills required to navigate the web and its intricacies (Chen 2013). Sundararajan (2016) describes social capital in the context of collaborative consumption as a signal of an individual's trustworthiness due to an extended network of social ties and also as a sign of reliability of an individual's commitment to an interaction. Arguing that making real-world social connectedness digitally available provides critical cues of authenticity, intent, and reliability, Sundararajan (2016) has contended social capital to be a pre-requisite for participating in many of today's sharing economy platforms. Additionally, it has been argued that community memberships and communal aspirations of the millennial generation is one determinant for practicing sharing or collaborating consumption (Möhlmann 2015). We therefore posit social capital, a construct comprised on four components based on the work of noted political scientist Robert Putnam to be positively associated with shared accommodation participation.

Attitudes towards Trust and Greener Consumption: Recent research on motivations and antecedents for participating in the sharing economy has repeatedly pointed to the importance of trust influencing participation (Hamari et al. 2016; Ramirez et al. 2016; Sundararajan 2016). With the advent and refinement of reputation ratings systems and other trust mechanisms, internet and software technologies have been increasingly employed to encourage good behavior by participants on the platforms. Academic literature, particularly in management information systems (MIS), examining trust as a construct and its antecedents, is extensive. In this paper, we incorporate trust into the conceptual model with a pair of proxy independents - do not use the internet (and phone) for banking transactions, and posit both to be negatively associated with shared accommodation participation by hosts.

Hamari et al. (2016) has contended that collaborative consumption is generally ecologically sustainable. Employing a similar argument, Sundararajan (2016) has contended that renting rather than owing, the premise behind collaborative consumption, holds the potential to preempt or at least delay the onset of future environmental crisis. We operationalize attitude towards sustainability using a proxy independent variable (proportion of population that believes helping to preserve nature is very important) and posit it to be positively associated with shared accommodation participation by hosts.

Dependent Variables in Conceptual Model: 16 dependent indicators of shared accommodation participation by hosts are part of the conceptual model. Each is a measure of density of Airbnb properties across 291 zip codes in the greater Los Angeles area for three types of accommodations: entire home/apartment, private room, and shared room. For example, two of the 16 dependent variables are zip code density of all types of accommodations for the years 2015-17, and density of private rooms in the year 2017.

Overall, the conceptual model of participation in shared accommodation-based economy by Airbnb hosts is novel for its associations of demographic, socio-economic, occupational, social capital, trust, and sustainability related independent variables with dependent density estimates. Exploratory spatiotemporal analysis of Airbnb property listing density and examination of spatial bias moderate the association between the model's independent and dependent variables.

\section{METHODOLOGY AND DATA}

\subsection{Methodology}

Our research methodology is comprised of the following steps: (1) Data on Airbnb property listings for the greater Los Angeles area for three kinds of properties - entire home/apartment, private room, and shared room - for three years, 2015, 2016, and 2017 were sourced from InsideAirbnb.com. Data for independent correlates of Airbnb property densities were collected from a variety of reliable sources. Descriptive statistics were computed for all variables, and Pearson correlation of independent variables were also computed to pre-screen multicollinearity. (2) Geocoded Airbnb property (entire home/apartment, private 
room, shared room) locations were first screened to ensure data completeness. All properties were mapped using a GIS and the number of properties by type (entire home/apartment, private room, shared room) were aggregated at the zip code level and subsequently the aggregated count was normalized per 1,000 population to obtain density of a specific type of Airbnb property as well as overall density per zip code in years 2015, 2016, and 2017. For example, density of entire home/apartment in zip code 90001 in $2017=$ (Total number of entire home/apartments in 90001 in 2017)/1,000 population. Property densities are proxies for host participation in the shared accommodation economy in this research. (3) Property densities were subsequently mapped to visualize spatial and temporal patterns of shared accommodations in the greater Los Angeles area. Descriptive mapping provides important visual cues about neighborhoods where hosts are more likely to participate in the shared accommodation economy compared to others. In addition, visualization of longitudinal changes in densities indicate shifts in shared accommodation participation in the study area. Figure 2 shows the density distribution of all listed Airbnb properties in the greater Los Angeles area.

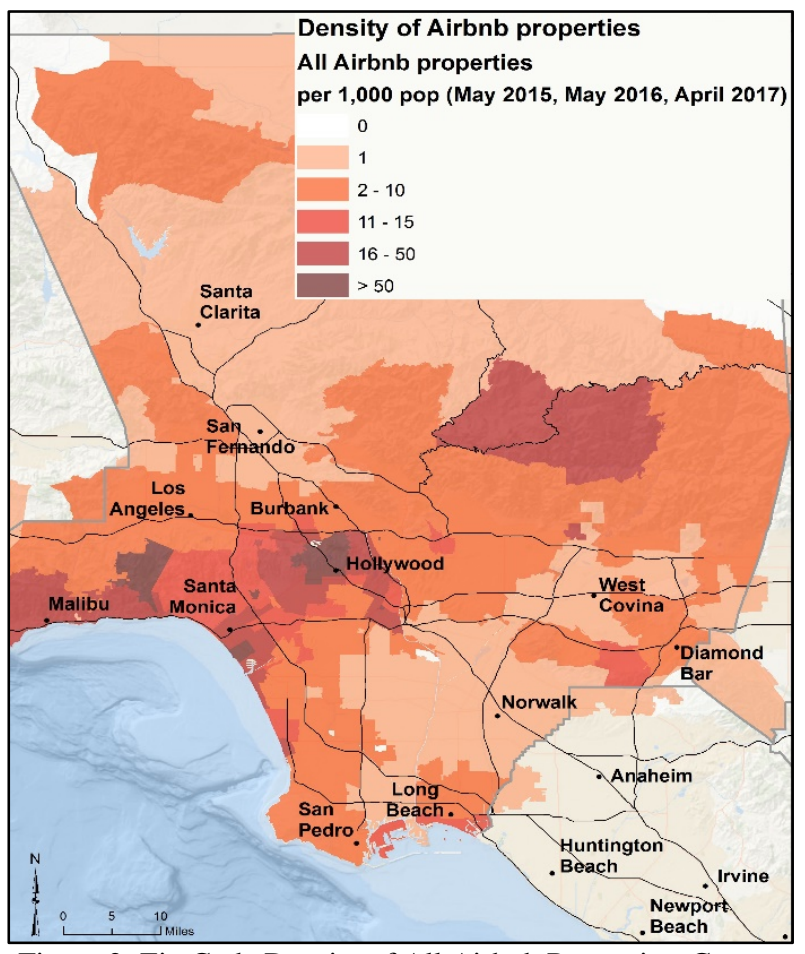

Figure 2. Zip Code Density of All Airbnb Properties, Greater Los Angeles, May 2015, May 2016, and April 2017 (combined)

(4) Next, we estimate spatial autocorrelation, a common pitfall plaguing most georeferenced phenomena, for all dependent density variables. It is motivated by a key question: whether participation in the shared accommodation economy shows statistically significant patterns of agglomeration of high and low values, or is it spatially randomly distributed. We diagnose spatial autocorrelation for each dependent density variable by using Moran's I test statistic. Moran's I test is inferential; the nul hypothesis is that the values of a variable are randomly distributed spatially (Openshaw 1984). Moran's I statistic for the dependent densities indicate how agglomerated zip codes are (positive value of Moran's I) in terms of property densities; if they are randomly distributed (Moran's I equals 0 ) or if a zip code with high density of Airbnb listings is surrounded by low density zip codes and vice versa (negative value of Moran's I). For Moran's I computations, inverse distance was used to conceptualize spatial relationships between Airbnb property densities in zip codes, and distances were computed using the Euclidean distance metric. (5) Subsequent to descriptive mapping of densities of Airbnb properties, we identify statistically significant clusters of shared accommodation economy participation by employing Local Indicators of Spatial Association (LISA) analysis (Anselin 1995). Local Moran's I statistic was estimated for each zip code (along with z-scores and p-values, using Inverse distance and Euclidean metric) to determine spatial clusters of zip codes with similarly high ("hotpots") or low (“coldspots") densities of Airbnb property listings. LISA analysis also identifies spatial outliers, in other words, if a zip code with high density of Airbnb property listings (indicating higher extent of participation) is surrounded by zip codes with low density of Airbnb property listings. Overall LISA analysis helps us to identify neighborhoods in the study area that are statistically significant agglomerations of shared economy participation, and allows us to critically examine these neighborhoods in terms of their locations and related attributes. This provides important clues about demographic and socioeconomic influences on shared economy participation, further confirmed by regression analysis. (6) Then, we conduct OLS regressions for each dependent variable, in stepwise fashion, allowing in only those independent variables with significance levels equal or less than 0.05 . As an additional test of multi-collinearity, the variance inflation factor (VIF) was computed for each independent variable. We utilize the common cut-off of 5 or greater for VIF to be of concern and no multicollinearity problems were detected. (7) Last, diagnostic testing using Joint Wald, Jarque-Bera, and Koenker (BP) statistics is administered to check if regression assumptions are met. Regression residuals are tested for spatial autocorrelation, also using Moran's I; model relationships that result in spatially random errors are regarded as valid.

\subsection{Data}

Data on dependent indicators of Airbnb listings were procured from InsideAirbnb.com, an independent, non-commercial set of tools and data that facilitates the exploration of how Airbnb is really being used in cities around the world. InsideAirbnb.com states that the data behind the visualizations available at the site data are sourced from publicly available information from the Airbnb site. Our Airbnb property listing data for the greater Los Angeles area span one day in each year 2015, 2016, and 2017 (May 24, 2015, May 2, 2016, and April 2, 2017). This provides longitudinal dimension to the study. All listings with availability fewer than 71 nights per year were removed, since the typical Airbnb listing in Los Angeles is rented 71 nights per year (Airbnb, 2016). After removal of listings with incomplete data (relatively few), 52,515 unique property listings, comprised of three types of accommodations, entire home/apartment, private room, and shared room, were mapped and found to spatially distributed across 291 zip codes in the greater Los Angeles area. The majority of listings were in 126 zip codes in the city of Los Angeles, while others were in neighboring cities such as Santa Monica to the west, Long Beach, Manhattan Beach, and Torrance to the south, Pasadena, La Canada Flintridge in the San Fernando Valley and cities of Lancaster and Palmdale in the Antelope valley to the north, and Baldwin Park, Claremont, and Covina to the east. These listings were mapped and subsequently aggregated and normalized by population to obtain Airbnb property densities at the zip code level.

Independent correlates (demographic variables such as young dependency ratio, gender ratio, race/ethnicity, and economic variables such as median household income, owner occupied 
households with a mortgage, employment in manufacturing, finance, insurance, and real estate, hotel/lodging, and professional, scientific, and technical services) of shared accommodation-based participation in the sharing economy were sourced primarily from Esri’s 2015 Demographics dataset, which is based on the U.S. Census Bureau's American Community Survey data. Social capital was a composite of four indicators of social connectedness based on the work of noted political scientist Robert Putnam: participation in a public activity, serving on a local committee, voting in an election, and volunteering for a charitable organization. Data for these components of the social capital construct as well as attitudes towards trust and greener consumption were sourced from Esri/GfK MRI DoubleBase Survey (Esri 2013). Variable definitions, sources, and descriptive statistics ( $\mathrm{n}=291$ zip codes) of dependent and independent variables are in Table 1.

\begin{tabular}{|c|c|c|c|c|c|c|c|}
\hline \multirow{17}{*}{ 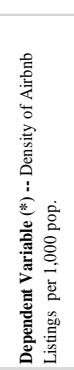 } & & Source & Year of Data & Minimum & Maximum & Mean & Std. Dev. \\
\hline & All accommodations, all years & \multirow{16}{*}{ 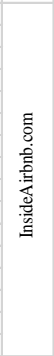 } & 2015-17 & 0.0000 & 1407.4073 & 11.3431 & 83.0361 \\
\hline & Entire home/apartment, all years & & 2015-17 & 0.0000 & 1074.0741 & 7.6273 & 63.3648 \\
\hline & Private Room, all years & & 2015-17 & 0.0000 & 296.2963 & 3.3259 & 17.5560 \\
\hline & Shared Room, all years & & 2015-17 & 0.0000 & 37.0370 & 0.3900 & 2.2160 \\
\hline & All accommodations, 2017 & & 2017 & 0.0000 & 592.5926 & 4.7856 & 34.9100 \\
\hline & Entire home/apartment, 2017 & & 2017 & 0.0000 & 518.5185 & 3.4375 & 30.5065 \\
\hline & Private Room, 2017 & & 2017 & 0.0000 & 74.0741 & 1.2185 & 4.4614 \\
\hline & Shared Room, 2017 & & 2017 & 0.0000 & 2.0275 & 0.1296 & 0.2667 \\
\hline & All accommodations, 2016 & & 2016 & 0.0000 & 444.4445 & 3.5698 & 26.2353 \\
\hline & Entire home/apartment, 2016 & & 2016 & 0.0000 & 370.3704 & 2.4732 & 21.8258 \\
\hline & Private Room, 2016 & & 2016 & 0.0000 & 74.0741 & 1.0154 & 4.4496 \\
\hline & Shared Room, 2016 & & 2016 & 0.0000 & 1.5954 & 0.0811 & 0.1696 \\
\hline & All accommodations, 2015 & & 2015 & 0.0000 & 370.3704 & 2.9877 & 21.9476 \\
\hline & ment, 2015 & & 2015 & 0.0000 & 185.1852 & 1.7165 & 11.1805 \\
\hline & Private Room, 2 & & 2015 & 0.0000 & 148.1481 & 1.0919 & 8.7101 \\
\hline & Shared Room, 2015 & & 2015 & 0.0000 & 37.0370 & 0.1793 & 2.1717 \\
\hline \multicolumn{8}{|c|}{ endent Variables * } \\
\hline \multirow{7}{*}{ Pemogr } & $\begin{array}{l}\text { Young Dependency Ratio (Pop. 0-19 } \\
\text { yr } / \text { Pop. 20-64 yr) }\end{array}$ & \multirow{13}{*}{ 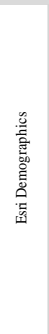 } & 2015 & 0.2126 & 2.9077 & 0.6268 & 0.1861 \\
\hline & Black (\%) & & 2015 & 0.0033 & 0.8322 & 0.0817 & 0.1249 \\
\hline & Asian (\%) & & 2015 & 0.0023 & 0.7073 & 0.1487 & 0.1431 \\
\hline & Hispanic (\%) & & 2015 & 0.0418 & 0.9773 & 0.4026 & 0.2576 \\
\hline & Male Age $21+/ \mathrm{Fe}$ & & 2015 & 0.7357 & 1.9209 & 0.9617 & 0.1490 \\
\hline & High School Graduate (\%) & & 2015 & 0.0399 & 0.3079 & 0.1782 & 0.0596 \\
\hline & Bachelors Degree (\%) & & 2015 & 0.0286 & 0.4755 & 0.2133 & 0.1054 \\
\hline \multirow{6}{*}{ Economic } & Median HH Income & & 2015 & 7500.00 & 200001.00 & 63603.32 & 29614.94 \\
\hline & $\begin{array}{l}\text { 2010-2014 ACS Owner Households } \\
\text { with a Mortgage (\%) }\end{array}$ & & 2015 & 0.0000 & 1.0000 & 0.7432 & 0.0985 \\
\hline & Manufacturing Employment (\%) & & 2015 & 0.0000 & 0.2417 & 0.1020 & 0.0443 \\
\hline & Finance, Insurance \& $\mathrm{R}$ & & 2015 & 0.0000 & 0.1980 & 0.0668 & 0.0300 \\
\hline & Prof, & & & 0.0000 & 0.2610 & 0.0831 & 0.0545 \\
\hline & & & 2015 & 0.0000 & 0.5124 & 0.0146 & 0.0438 \\
\hline Social $\mathrm{C}$ & $\begin{array}{l}\text { Average of participation in public activity, } \\
\text { serving on locac comminttee, voting in election, } \\
\text { and voluntering for charitable org }(\%)\end{array}$ & \multirow{5}{*}{ 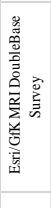 } & 2016 & 0.2246 & 0.5099 & 0.3613 & 0.0689 \\
\hline \multirow{2}{*}{$\begin{array}{c}\text { Attitude } \\
\text { towards trust }\end{array}$} & $\begin{array}{l}\text { Do not use Internet for banking } \\
\text { transactions (\%) }\end{array}$ & & 2016 & 0.1135 & 0.3151 & 0.2039 & 0.0341 \\
\hline & $\begin{array}{l}\text { Do not use phone for banking } \\
\text { transactions (\%) }\end{array}$ & & 2016 & 0.2024 & 0.3427 & 0.2757 & 0.0199 \\
\hline \multirow[t]{2}{*}{$\begin{array}{l}\text { Attitude for } \\
\text { Greener } \\
\text { Consumption }\end{array}$} & $\begin{array}{l}\text { Helping to preserve nature very } \\
\text { important (\%) }\end{array}$ & & 2016 & 0.4736 & 0.7588 & 0.6996 & 0.0330 \\
\hline & $* n=291$ & & & & & & \\
\hline
\end{tabular}

Table 1. Descriptive Statistics of Variables

\section{SPATIOTEMPORAL PATTERNS OF SHARED ACCOMMODATIONS}

Discussion of spatiotemporal patterns of host participation in the shared accommodation economy is split into three parts. First, we examine spatial distributions and temporal changes in host participation, measured by Airbnb listing density in the greater LA area. This is followed by discussion on spatial clusters of host participation indicating "hotpots" as well as "coldspots" of shared accommodations, based on LISA analysis. LISA analysis also helps to identify areas (zip codes) that are considered outliers. We comment on temporal fluctuations of such clusters and outliers. Finally, we discuss the influence of spatial autocorrelation on host participation in the shared accommodation market. This is important since in order to effectively analyze demographic, socio-economic, occupational, social capital, trust, and sustainability's influence on host participation, it is essential to diagnose and analyze the extent of spatial bias in participation.

Spatial Patterns: Descriptive mapping of densities of three types of Airbnb property listings (entire home/apartment, private room, and shared room in 2015, 2016, and 2017) indicates that host participation is highest in parts of the city of Los Angeles, coastal communities such as Venice and Marina Del Ray, Malibu, and the city of Santa Monica. In fact, host participation over the 3-year period 2015-17 is generally high all along the Pacific coastal communities stretching from Malibu all the way south to Long Beach. This is likely due to properties that are listed on Airbnb due to their proximity to the ocean often offering panoramic views of the shoreline. Further inland within the city of LA, neighborhoods that are popular tourist destinations and hubs of entertainment, arts, and culture such as West Hollywood, Beverly Hills, and Studio City (home to Universal Studios CA) have exhibited high host participation. Host participation declines north of Burbank in the San Fernando Valley, Santa Clarita, all the way up to the Antelope Valley. Host participation is also low in communities further inland bordering San Bernardino County and in densely populated working class neighborhoods southsoutheast of LA (e.g., Compton, Downey, Paramount, Bellflower, Lakewood, Cerritos, and Norwalk). Several of these communities have local economies based on traditionally "blue-collar" transportation/ logistics businesses due to their proximity to Long Beach and Los Angeles ports.

Cluster and outlier analysis reveals two distinct clusters (Figure 3) that are hotspots of host participation - one that is in downtown Los Angeles comprised of popular entertainment venues, fashion district, downtown arts district, and ethnic enclaves such as Koreatown, Chinatown and Little Tokyo, continuing north to Hollywood and Glendale bordering famous LA landmarks such as the Griffith Observatory and Hollywood sign. The other hotspot is in the coastal city of Santa Monica and the community of Pacific Palisades. Together, these hotspots of host participation account for 16 zip codes out of 291 in the greater LA study area between 2015 and 2017. Conversely, communities north of Los Angeles (specifically 27 zip codes) are coldspots of host participation; they are located in the Santa Clarita Valley communities such as Valencia all the way north to the Antelope Valley communities of Lancaster and Palmdale possibly indicating the nascence of the shared accommodation market in these cities. As evident from Figure 3, two mutually disjoint sets of communities - one south-southwest of Hollywood-Downtown and the other east of Downtown Los Angeles, comprised of 16 zip codes are low-high outliers. In other words, these communities that have low participation in shared accommodation-based economy are in close proximity to areas with high participation and therefore are statistically significant outliers in terms of participation. We reason that these medium-low income densely populated communities possibly do not offer the luxury of spare space or amenities that would make them attractive to prospective Airbnb renters.

Temporal Patterns: Unsurprisingly, the largest growth in host participation between 2015 and 2017 has also been in coastal communities along the Pacific coastline (Malibu, Venice, Playa Vista, Marina Del Ray) along with West Hollywood, Beverly Hills, and Calabasas. Interestingly however, communities further inland that are suburbs of Los Angeles to its north (Glendale, Duarte) and east (Pomona, Diamond Bar, El Monte, Alhambra) have witnessed an at least $200 \%$ growth in density of property listings between 2015 and 2017. Conversely, growth in host participation has been comparatively slower in inland, densely populated, blue-collar communities in greater Los Angeles such as Downey, Gardena, Covina, Lakewood, Bell Gardens, Baldwin Park, and others.

Longitudinally, the proportion of zip codes that contain statistically significant "hotspots" (high-high clusters) of shared rooms increased from close to $2 \%$ of all greater LA zip codes in 
2015 to close to 20\% in 2016 (see Table 2). The growth in statistically significant "coldspots" and "low-high" outliers while not as stark was noticeable nonetheless. Similar spatiotemporal diffusion of clusters of private rooms (hotspots as well as coldspots) was also noticeable in the 2015-17 period. Conversely, statistically significant hotpots of entire home/apartments declined between 2015 and 2017. We attribute this overall pattern of spatiotemporal diffusion of clusters and outliers of the different types of accommodations to the low barrier of entry into the shared accommodation market posed by room-sharing by hosts compared to renting an entire home/apartment.

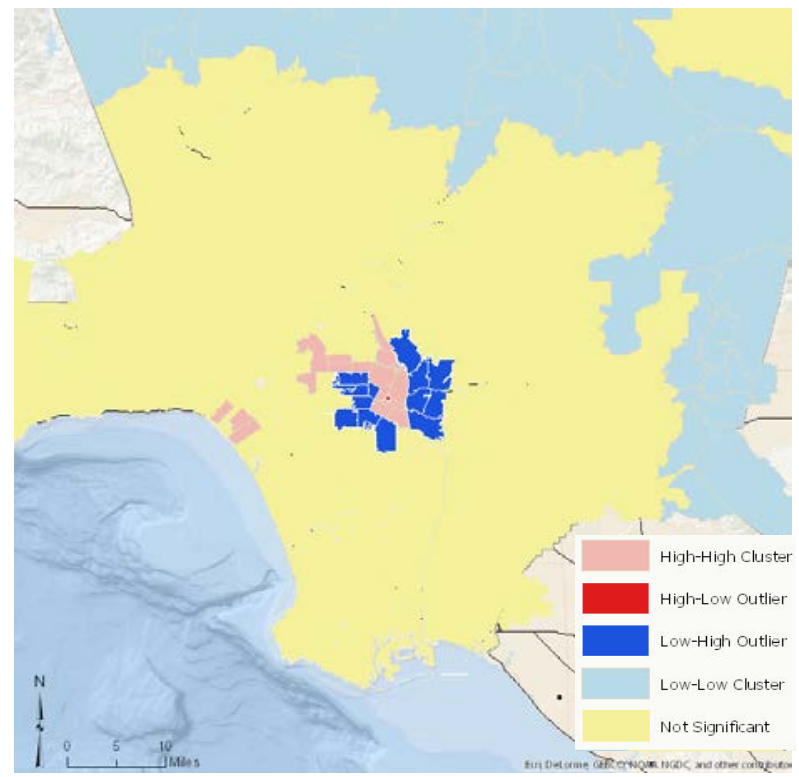

Figure 3. LISA Clusters of Airbnb Property Densities, 2015-17

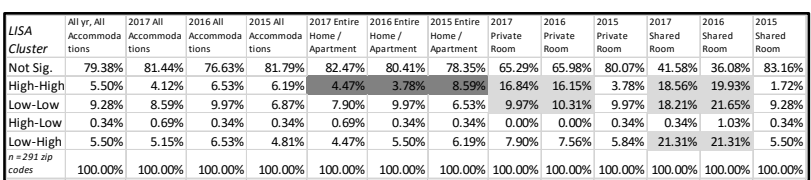

Table 2. Proportions of zip codes in LISA clusters, 2015-17, for various types of Airbnb accommodations

We conclude this discussion of spatiotemporal patterns of shared accommodations by observing that participation in the shared accommodation economy as measured by density of Airbnb property listings has very low spatial autocorrelation, as evidenced by Moran's I values that are close to zero in Table 3. However, participation is significantly spatially autocorrelated (at $\mathrm{p}<.01$ and oftentimes at $\mathrm{p}<.001$ levels) for all types of accommodations (entire home/apartment, private room, shared room) in 2016 and 2017. In 2015, we do not find evidence of spatial autocorrelation for private rooms and shared rooms indicating the nascence of these accommodations and their spatial dispersion in the greater LA area. Among property types, there is negligible difference between the extents of spatial autocorrelation between the three types of accommodations. Despite low values, presence of spatial autocorrelation in participation has implications for subsequent OLS regression analysis of associations of various independent variables with dependent indicators of participation.

\section{SOCIOECONOMIC CORRELATES OF HOST PARTICIPATION}

The important socioeconomic correlates are seen in the regression findings in Table 3 include economic, employment, income, age, sex ratio, and ethnicity variables. The findings are first considered for the four categories of accommodation types for the three years combined of 2015-2017. After that differences in the individual years of 2015, 2016, and 2017 are examined for longitudinal analysis.

For combined years, the overall regressions are highly significant, with adjusted r-square values of 0.407 to 0.413 , implying that 40 to 42 percent of the variance of dependent variables is accounted for by the model. The most significant predictor of Airbnb property density is the inverse of owner occupied households with a mortgage, in other words, households lacking a mortgage. Although this sometimes occurs with very affluent homeowners, it is more likely an attribute of low-income homeowners, who are not eligible to gain mortgage financing. In such a circumstance also, the homeowner is seeking additional income, both for augmentation of income for the person or family or to increase eligibility to receive a mortgage.

Also significant is employment in finance, insurance, and real estate (FIRE) occupations. Owners residing in zip codes high in FIRE occupations would be more likely to understand real estate and hospitality aspects of the sharing economy and to have access to services related to real estate and finance. The most significant relationship is that median household income is associated with reduced density of Airbnb accommodations. In other words, lower income areas have higher density of Airbnb. The explanation is - households in lower income areas are more likely to supplement their income through the sharing economy.

A higher presence of children and adolescents in households for a zip code is associated with reduced Airbnb density. This is understandable through the need to maximize room use, eliminating rental of entire homes or spare rooms either private or shared. Even if a spare room is available for renting, parents may be disinclined to allow strangers into the home with children or teens present. In zip codes having higher sex ratios (age 15+), i.e. with greater gender proportion of males, there is a higher Airbnb density, which may reflect generally more inclination for males to be Airbnb hosts (Rossa et al, 2015).This might be because of less anxiety about risk of unruly tenants.

There is weak but significant association of manufacturing employment with Airbnb density. This small effect is unexplained. Finally, the inverse effect of Asian ethnicity with all accommodations and with entire home/apartment accommodations underscores that Asians who are more prosperous than the overall population might be less inclined as owners to share their home premises to short-term guests or longer term tenants. This is in concert with the explanation for the inverse association of median income with Airbnb density. A unique association for positive attitude towards green consumption with private room Airbnb accommodation may reflect the motivation of environmentally-driven owners not to waste the space of empty spare rooms that are nevertheless causing environmental externalities. It might be that such owners prefer a moderate environmental benefit, i.e. to do short-term rentals of single room rather than shared room or entire home for longer periods.

Comparison of the regression findings for each of the three years indicates relatively little change in effects. Predominantly, the findings for the overall three-year period is similar to those for each of the three years. Hence this section only points out differences from year to year, as follows: (1) The changes between the years primarily involve differences in correlates for shared room accommodations. (2) In 2015, shared room 
accommodations reflect the same results as for the 3-year period, except that manufacturing employment is additionally a correlate for 2015, an unexplained finding. (3) In 2016, shared room accommodations, compared to the 3-year period is missing an income effect, but does have a significant educational effect, i.e. higher education in the zip code is related to owners who participate in Airbnb with shared rooms. It also adds an inverse effect of Asian ethnicity. (4) In 2017, shared room accommodation, compared to the 3-year period, does not have the inverse effect with age, has an inverse Asian effect, education effect and inverse effect with lack of trust, as reflected in the proxy of no using phones for bank transactions.

Finally, as evident from Table 3, Moran's I of regression residuals is statistically significant for only 3 out of the 16 regressions. Therefore, the proposed model of host participation is largely robust and accounts for spatial autocorrelation of dependent variables, estimated by densities of listed Airbnb properties. This is a significant contribution of this work.

\subsection{Discussion}

Overall, this study reports on new findings that heretofore have not been studied at the zip code level in a major city. Findings can be compared to a study that includes analysis of homesharing services from the demand perspective (Smith, 2016), rather than the supply. The primary finding on the strong association of homeowners without mortgages with Airbnb property density can be justified by the benefits from sharing economy occupations for workers to supplement their incomes (Rossa, 2015). Persons denied mortgages are often younger people who have not built up an income stream or have limited income and wish to diversify income sources. For example college students are known to be looking for supplemental income (Rossa, 2015), and that might apply to somewhat older young adults who purchase a home, condo, or apartment, but have a challenge to obtain or maintain a mortgage. The small proportion of wealthy people who do not need a mortgage or have paid up fully on their mortgages would have an opposite effect of reducing density of Aribnb mortgages, which is reinforced in the inverse association of income with density of Airbnb accommodations.

The second strongest determinant of Airbnb density is finance, insurance, and real estate (FIRE) occupations. That association might stem from the Airbnb host residing in an area having a greater understanding of real estate, accommodations, hospitality service connected with real estate. The Airbnb guests and hosts are seeking this kind of understanding, in particular they seek lower rental pricing, charming locations, and personalized services (Sundararajan, 2016). They would like personal space and personal attention, almost the feel of one's home. Those qualities are more likely to be present in areas with a strong presence of real estate and related services, reflected by high per capita FIRE employment. Further, if the owner himself/herself is from real estate and related sub-industries, the potential grows for participation in shared accommodations as a host.

The inverse effect of income, i.e. low average household income being associated with high Airbnb density is the direct result of the potential for members of the sharing economy workforce to diversify income sources (Rossa, 2015). This aspect is reflected in the very strong attitude among home-sharing users that the owners sharing their premises to guests are benefited by being able to earn extra income (Smith, 2016). The association of high proportion children/youth with lower Airbnb density is likely due to the concerns expressed earlier about safety and security aspects of renting out rooms to strangers in a home with children. On the other hand, from a guest/host view, shared accommodations are viewed overwhelmingly as "as good option for families or others who travel as a group" (Smith, 2016). Perhaps a family group having children and teens feels greater sense of safety through the familial trusting environment being present in the renting group.

The two ethnicities have substantial influence. There is the association of proportion Black with Airbnb density. This association is present for the combined years only for private room accommodations, but for the individual years of 2015, 2016, and 2017 it is widely and significantly present. This finding is contrary to some public attitudes that shared accommodation density is located away from areas with higher Black population per capita. For combined years, proportion Asian is weakly inversely associated with all accommodations. This finding needs more research for full explanation.

Several posited variables had little or no association with Airbnb densities, including education factors, professional / technical / service employment, social capital, two proxy variables for trust, and Hispanic ethnicity. The absence of effects of these variables might pertain just to the metropolitan region of Los Angeles, and bear inclusion in studies of other metropolitan areas to determine whether their absence is more generally present.

\section{CONCLUSIONS}

This paper is the first systematic attempt to examine spatiotemporal patterns of host participation in the shared accommodation economy. As sharing economy platforms disrupt traditional business models, academic interest in understanding digital determinants, socioeconomic drivers, and other influences on sharing economy participation is on the rise. A few reports have shed light on why individuals participate in the sharing economy as consumers. However research on who are the sharing economy workers, why do hosts share accommodations has heretofore been scantly studied. In addition to examining spatiotemporal patterns, this study develops a conceptual model and tests associations of demographic, socioeconomic, occupational, social capital influences along with associations of hosts' attitudes to trust and sustainability with participation in the shared economy. Results indicate that host participation is inversely associated with young dependency ratio, median household income, and owner occupied households with a mortgage, and positively associated with gender ratio (male/female). Additionally, positive association of employment in finance, insurance, and real estate with host participation is found. Overall, this implies that unlike ridesharing workers, shared accommodation hosts are likely to be older; however other sharing economy workers, shared accommodation hosts are also motivated by the potential of supplemental income. This study's novel findings also include positive association of attitude towards greener consumption indicating that shared accommodation hosts are likely to participate in the sharing economy motivated by ecological sustainability of collaborative consumption.

More work is needed to confirm generalizability of this study's findings for sharing economy platforms in industries other than hospitality. It is also essential to test the robustness of the proposed model for other U.S. and nonU.S. markets where shared accommodation platforms such as Airbnb have gained strong foothold. Furthermore, understanding of spatial and temporal patterns will be strengthened as more longitudinal data on shared accommodation listings in diverse markets becomes 
available. As acknowledged earlier in this paper, further research is required to incorporate proxies for attitudes towards trust and greener consumption as independent correlates. This can be informed by significant work that exists in literature in other disciplines, most notably MIS.

\section{ACKNOWLEDGEMENTS}

The authors gratefully acknowledge the valued data processing, mapping, and computational assistance provided by Ms. Lisa Benvenuti, Spatial Resources Manager, Center for Spatial Studies, at the University of Redlands.

\section{REFERENCES}

Airbnb. 2016. “Airbnb’s Economic Impact in Los Angeles in 2016,” (available at https://los-angeles.airbnbcitizen.com/economic-impactreports/airbnbs-economic-impact-los-angeles-2016/).

Anselin, L. 1995. "Local Indicators of Spatial Association-LISA," Geographical Analysis (27:2), pp. 93-115 (doi: 10.1111/j.15384632.1995.tb00338.x).

Benner, K. 2015. "On-Demand Begins March on White-Collar Professions; 'Uber Legal' to Come?,” Bloomberg Brief (available at https://newsletters.briefs.bloomberg.com/document/4vz1acbgfrxz8uwan 9/front).

Bocker, L., and Meelen, T. 2016. "Sharing for people, planet or profit? Analysing motivations for intended sharing economy participation," Environmental Innovation and Societal Transitions (doi: 10.1016/j.eist.2016.09.004)

Chen, W. 2013. "The Implications of Social Capital for the Digital Divides in America," The Information Society (29:1), pp. 13-25 (doi: 10.1080/01972243.2012.739265)

Esri. 2013. "US market potential data methodology statement,” Esri ${ }^{\circledR}$ White Paper, p.6 (available a http://support.esri.com/en/knowledgebase/whitepapers/view/productid/1 53/metaid/2037)

Gutierrez, J., Garcia-Palomares, J. C., Romanillos, G., and SalasOlmedo, M. H. 2016. “Airbnb in tourist cities: comparing spatial patterns of hotels and peer-to-peer accommodation,” arXiv preprint arXiv:0812.1045, p. 17

Hamari, J., Sjöklint, M., and Ukkonen, A. 2016. "The sharing economy: Why people participate in collaborative consumption," Journal of the Association for Information Science and Technology (67:9), pp. 20472059 (doi: 10.1002/asi.23552).
Kim, J., Yoon, Y., and Zo, H. 2015. "Why People Participate in the Sharing Economy: A Social Exchange Perspective," in PACIS 2015 Proceedings (Vol. Paper 76), pp. 1-6 (available at http://aisel.aisnet.org/pacis2015).

Koohikamali, M., Sarkar, A., and Pick, J. 2017. "Motivations to participate in sharing economy: How location matters?," in Americas Conference on Information Systems, Boston: AIS, pp. 1-5.

Matzler, K., Veider, V., and Kathan, W. 2015. “Adapting to the Sharing Economy,” MIT Sloan Management Review (56:2), p. 10.

Mittendorf, C. 2017. "The Implications of Trust in the Sharing EconomyAn Empirical Analysis of Uber," Proceedings of the 50th Hawai International Conference on System Sciences, pp. 5837-5846 (available at http://scholarspace.manoa.hawaii.edu/handle/10125/41866).

Möhlmann, M. 2015. "Collaborative consumption: Determinants of satisfaction and the likelihood of using a sharing economy option again," Journal of Consumer Behaviour (14:3), pp. 193-207 (doi: 10.1002/cb.1512).

Openshaw, S. 1984. The Modifiable Areal Unit Problem (MAUP), Geobooks, Norwich, England.

Pick, J. B., Sarkar, A., and Johnson, J. 2015. "United States digital divide: State level analysis of spatial clustering and multivariate determinants of ICT utilization,” Socio-Economic Planning Sciences (49), pp. 16-32 (doi: 10.1016/j.seps.2014.09.001).

Pick, J., and Sarkar, A. 2015. The global digital divides: Explaining change, Springer.

Ramirez, E., Ohlhausen, M. K., and McSweeny, T. P. 2016. “The Sharing Economy: Issues Facing Platforms, Participants, and Regulators,” Federal Trade Commission (FTC) (Vol. 8205).

Rossa, J., Crombie, J., Riley, A., and Fretz, D. 2015. "The Sharing Economy," Bloomberg Brief (available at https://newsletters.briefs.bloomberg.com/document/4vz1acbgfrxz8uwan 9/front).

Smith, A. 2016. "Shared, Collaborative and On Demand: The New Digital Economy," (available at http://www.pewinternet.org/2016/05/19/the-new-digital-economy/).

Sundarajan, A. 2013. "From Zipcar to the Sharing Economy," Harvard Business Review.

Sundararajan, A. 2016. The Sharing Economy: The End of Employment and the Rise of Crowd-Based Capitalism (available at https://books.google.com/books?id=F-iEjgEACAAJ\&pgis=1).

Zhang, K., Yan, R., and Zhao, S. 2016. "Understanding Participation in Sharing Economy: The Role of Convenience, Risk, and Regulatory Foci,” in Pacific Asia Conference on Information Systems, Chiayi, Taiwan: AIS, p. 11

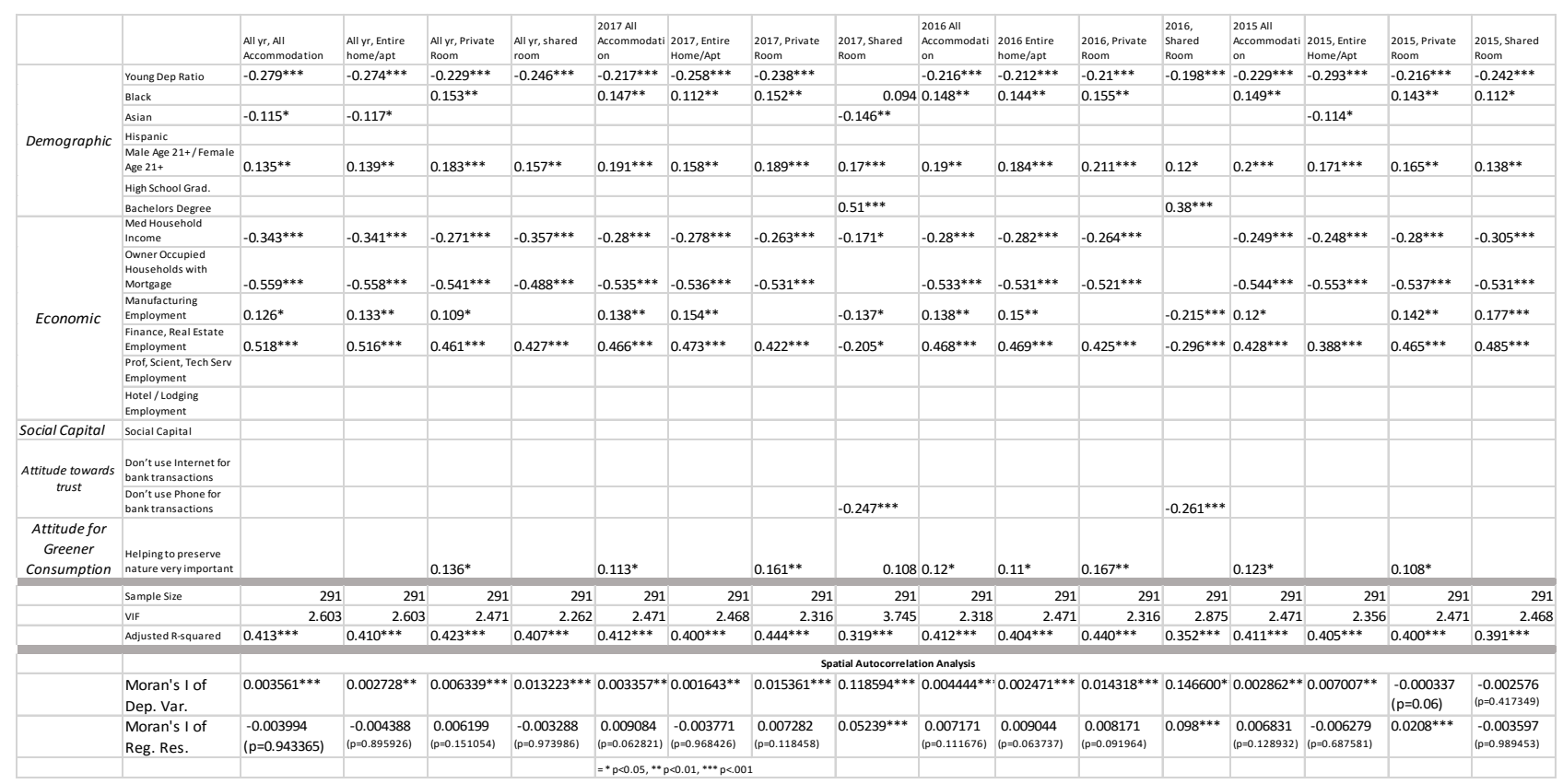

Table 3. Regression Results, Greater Los Angeles, 2015-17, for various types of Airbnb accommodations 